\title{
Effect of a Caries-detecting Solution on the Tensile Bond Strength of Four Dentin Adhesive Systems
}

\author{
Haruka YOKOTA, Shisei KUBO, Hiroaki YOKOTA, Masahiro OHSAWA and Yoshihiko HAYASHI \\ Division of Cariology, Department of Developmental and Reconstructive Medicine, Course of Medical and Dental Sciences, \\ Nagasaki University Graduate School of Biomedical Sciences, 1-7-1, Sakamoto, Nagasaki 852-8588, Japan \\ Corresponding author, Haruka Yokota E-mail:yokoharu@net.nagasaki-u.ac.jp
}

Received September 7, 2005/Accepted November 28, 2005

\begin{abstract}
This study investigated the effect of a caries-detecting solution on the tensile bond strength (TBS) to sound bovine dentin - which was either rinsed thoroughly of or contaminated with the caries-detecting solution.

Caries Detector (1.0\% acid red in propylene glycol) was applied on flat dentin surfaces for 10 seconds, rinsed, and dried with syringe air. In another group, Caries Detector was not rinsed but air-dried. Then, the surfaces were treated with one of the following adhesive systems: Clearfil Protect Bond, Clearfil SE Bond, One-Up Bond F, or Single Bond. Furthermore, an ingredient of Caries Detector, either 1.0\% acid red aqueous solution or propylene glycol, was applied to evaluate the effect of each component. In the control groups, Caries Detector was not applied to the dentin surfaces. Finally, a resin composite was light-cured and the TBS measured. Fractured specimens and treated dentin surfaces were observed by SEM. Caries Detector did not reduce the tensile bond strength of any adhesive system $(p>0.05)$ when rinsed thoroughly. On the other hand, when dentin surface was contaminated with Caries Detector, TBS decreased significantly with Clearfil SE Bond and Single Bond. As for the ingredients of Caries Detector, the effect of acid red on TBS was not significant, but that of propylene glycol was significant.
\end{abstract}

Key words: Caries-detecting solution, Tensile bond strength, Adhesive system

\section{INTRODUCTION}

Of late, there has been increased interest in the socalled Minimal Intervention Dentistry $(\mathrm{MI})^{1)}$ concept - new techniques of dental caries treatment with less surgical intervention. The development of resin composite restorative systems - that bond to tooth substance and which possess good physical properties has enabled MI, so that only caries-infected dentin is removed and the cavity form does not require mechanical retention $^{2,3)}$. Thus, it can be said that MI helps to preserve the maximum sound dentin.

Carious dentin consists of two distinct layers with different ultramicroscopic structures and chemical compositions ${ }^{4,5)}$. Outer carious dentin (cariesinfected dentin) is completely infected, insensitive, unremineralizable, and contains irreversibly deteriorated collagen fibers: it should therefore be removed. Inner carious dentin (caries-affected dentin) is uninfected, sensitive, remineralizable, and contains reversibly denatured collagen fibers - which should be preserved $^{6)}$. Therefore, in order to clinically differentiate these two layers, caries-detecting solutions have been developed ${ }^{7,8)}$.

Although caries-affected dentin and/or abradedsclerotic dentin are frequently substrates for adhesive restorative materials in clinical situations, bonding studies are usually performed on normal dentin ${ }^{9}$. However, the development of microtensile bond strength test method has enabled the bond strength to caries-affected or abraded-sclerotic dentin to be measured $^{10-12)}$. It has been reported that bond strength to caries-affected dentin is significantly lower than that to normal dentin ${ }^{13-19)}$. The lower bond strength is probably due to the presence of acid-resistant mineral deposits in the dentinal tubules and adjacent intertubular dentin ${ }^{13-19)}$. However, it cannot be denied that in these studies, the usage of Caries Detector (1.0\% acid red in propylene glycol) might have also affected the bond strength to cariesaffected dentin.

Concerning the effect of caries-detecting solutions (colorant in propylene glycol or colorant in propylene glycol aqueous solution) on bond strength to sound dentin, opinions from both camps have been duly expressed. Some studies reported that shear bond strength was not affected ${ }^{20)}$, whereas some studies indicated a significant decrease in tensile bond strength ${ }^{21)}$. However, no studies have reported on the effect of Caries Detector application on bond strength.

In general, the caries-detecting solution is rinsed away thoroughly before dentin priming. However, when performing an MI restoration in a clinical situation, the access opening could be so small that some parts of the cavity wall are hidden from sight. This is especially so with Class III cavities, and the situation is exacerbated when the operator cannot use the mirror technique well. Under such circumstances, there is a fear that the caries-detecting 
solution is not rinsed away thoroughly and still remains on the dentin surface.

This study was therefore designed to investigate the effect of Caries Detector on the tensile bond strength of four adhesive systems to sound bovine dentin, when the caries-detecting solution was either rinsed away thoroughly or remained on the dentin surface without rinsing.

\section{MATERIALS AND METHODS}

Materials used

Tables 1 and 2 indicate the restorative and other materials used in this study.

\section{Tensile bond strength evaluation}

1 ) Specimen preparation

The structures of bovine enamel and dentin resemble those of humans ${ }^{22,23)}$. Therefore, bovine teeth can be used as a substitute for human teeth in in vitro bond strength and microleakage studies ${ }^{24,25)}$ - and they indeed have been used in many previous studies ${ }^{26-34)}$. Bovine incisors (at least three years old) were used in this study. They were kept frozen $\left(-18^{\circ} \mathrm{C}\right)$, and then defrosted in tap water just before use. Maximum storage period of tooth specimens was six months.

Flat coronal dentin surfaces were prepared on the labial surface of bovine teeth, which were then embedded in slow-curing epoxy resin (SpeciFix-20, Struers A/S, Copenhagen, Denmark). Upon setting of epoxy resin (after about 24 hours), the flat dentin surfaces were finished with wet 800-grit silicon carbide papers under running water and then divided into one of the following groups:

- In the first group, a caries-detecting solution, Caries Detector (Table 1), was applied to the surfaces for 10 seconds, rinsed for five seconds,

Table 1 Materials used in this study

\begin{tabular}{ll}
\hline \multicolumn{1}{c}{ Material } & \multicolumn{1}{c}{ Composition } \\
\hline $\begin{array}{l}\text { Caries Detector } \\
\text { (Kuraray Medical Inc., Okayama, Japan) }\end{array}$ & $1.0 \%$ acid red in propylene glycol \\
$\begin{array}{l}\text { Acid Red 52 } \\
\text { (Wako Pure Chemical Industries Ltd., Osaka, Japan) }\end{array}$ & $\mathrm{C}_{27} \mathrm{H}_{29} \mathrm{~N}_{2} \mathrm{NaO}_{7} \mathrm{~S}_{2}=580.64$ \\
$\begin{array}{l}\text { Propylene glycol } \\
\text { (Wako Pure Chemical Industries Ltd., Osaka, Japan) }\end{array}$ & $\mathrm{CH}_{3} \mathrm{CH}(\mathrm{OH}) \mathrm{CH}_{2} \mathrm{OH}=76.10$ \\
\hline
\end{tabular}

Table 2 Restorative materials used in this study

\begin{tabular}{|c|c|}
\hline Adhesive system & Composition \\
\hline $\begin{array}{l}\text { Clearfil Protect Bond } \\
\text { (Kuraray America Inc., New York, USA) } \\
\text { Two-step self-etching primer adhesive system conta }\end{array}$ & $\begin{array}{l}\text { Primer: MDP, HEMA, MDPB, water } \\
\text { Bond: MDP, HEMA, NaF, microfiller }\end{array}$ \\
\hline $\begin{array}{l}\text { Clearfil SE Bond } \\
\text { (Kuraray Medical Inc., Okayama, Japan) } \\
\text { Two-step self-etching primer adhesive system }\end{array}$ & $\begin{array}{l}\text { Primer: MDP, HEMA, water } \\
\text { Bond: MDP, HEMA, microfiller }\end{array}$ \\
\hline $\begin{array}{l}\text { One-Up Bond F } \\
\text { (Tokuyama Co., Tokyo, Japan) } \\
\text { Single-step self-etching 'all-in-one' adhesive system }\end{array}$ & $\begin{array}{l}\text { Bonding Agent A: Mac-10, methacryloyloxyalkyl acid } \\
\text { phosphate } \\
\text { Bonding Agent B: HEMA, water, fluoroaluminosilicate } \\
\text { glass }\end{array}$ \\
\hline $\begin{array}{l}\text { Single Bond } \\
\text { (3M ESPE Dental Products, St. Paul, MN, USA) } \\
\text { Two-step single-bottle adhesive system }\end{array}$ & $\begin{array}{l}\text { Etchant: } 35 \% \text { phosphoric acid } \\
\text { Adhesive: polyalkenoic copolymer, Bis-GMA, HEMA, } \\
\text { ethanol, water }\end{array}$ \\
\hline $\begin{array}{l}\text { Clearfil AP-X } \\
\text { (A3, Kuraray Medical Inc., Okayama, Japan) } \\
\text { Hybrid type }\end{array}$ & Bis-GMA, TEGDMA, barium glass, colloidal silica, CQ \\
\hline
\end{tabular}

Abbreviations: MDP, 10-methacryloyloxydecyl dihydrogen phosphate; HEMA, 2-hydroxyethylmethacrylate; MDPB, 12-methacryloyloxydodecylpyridinium bromide; Mac-10, 11-methacryloxy-1,1-undecanedicarboxylic acid; $\mathrm{CQ}$, dl-camphorquinone 
and then air-dried thoroughly (abbreviated as r-a hereafter).

- In the second group, Caries Detector was also applied on the dentin surfaces and dried by a gentle air stream for five seconds (abbreviated as a-d hereafter).

- For the control groups, Caries Detector was not applied.

The surfaces were then covered with a piece of adhesive tape with a 4-mm diameter hole to demarcate the bonding area. Prepared dentin surfaces were then treated with Clearfil Protect Bond (Table 2), Clearfil SE Bond (Table 2), One-Up Bond F (Table 2 ), or Single Bond (Table 2) according to the manufacturer's instructions. For the four adhesive systems, either $1.0 \%$ acid red aqueous solution (Table 1) or propylene glycol (Table 1) - both of which were ingredients of Caries Detector - was applied to the sound dentin surfaces. Neither ingredient was rinsed away, but merely air-dried with a gentle air stream for five seconds. A slightly reverse-tapered brass ring ( $4 \mathrm{~mm}$ in diameter and $2 \mathrm{~mm}$ in height) was then placed on the tape. A resin composite (Clearfil AP-X, Table 2) was inserted in a bulk form and cured for 60 seconds using a curing unit (New Light VL-II, GC Corp., Tokyo, Japan). Ten specimens were prepared for each group. Light intensity output of the curing unit was checked periodically with a radiometer (Curing Radiometer Model 100, Demetron Research Corp., Danbury, CT, USA) to ensure that it was above $500 \mathrm{~mW} / \mathrm{cm}^{2}$.

2 ) Tensile bond strength testing

After storage in tap water for 24 hours, the specimens were set in a device for tensile bond strength testing where bond strength was measured using a universal testing machine (Autograph DSS 500, Shimadzu Co., Tokyo, Japan) at a cross-head speed of $1 \mathrm{~mm} / \mathrm{min}$. Tensile bond strength was calculated by dividing the failure load by the bonded area.

Mean values for each treating condition and each adhesive system were assessed using one-way ANOVA followed by a post-hoc Tukey-Kramer multiple comparison test to find out if there were any significant differences $(p<0.05)$. Dunnett's test was used to compare the mean value of the control group in each adhesive system against the other four treating conditions $(\mathrm{p}<0.05)$.

\section{SEM evaluation}

1) Fractured specimens

Following the tensile bond test, all fractured specimens were examined under a light microscope (XFBD, Nikon, Tokyo, Japan) at $\times 100$ magnification to determine the mode of failure. In addition, the failure modes of some representative fractured surfaces were ion-coated with gold using an ioncoating device (IB-2, Eiko Engineering Ltd., Ibaraki, Japan) and observed with a scanning electron microscope (SEM) (S3500N, Hitachi, Tokyo, Japan) at 20 $\mathrm{kV}$ accelerating voltage $(\times 30$ and $\times 1,500$ magnification).

2 ) Treated dentin surfaces

Treated dentin surfaces in all groups were observed with a SEM. The procedure was performed in the same way as for the bond strength measurement until the dentin surface treatment with self-etching primer, self-etching adhesive, or $35 \%$ phosphoric acid. The specimens (except for Single Bond) were rinsed with acetone to remove resin component in the selfetching primer or self-etching adhesive, dehydrated in ascending concentrations of ethanol, and subjected to critical point drying (HCP-2, Hitachi, Tokyo, Japan). Finally, all specimens were similarly ion-coated and examined with a SEM (x3,000 magnification).

\section{RESULTS}

\section{Tensile bond strength}

Table 3 shows the mean tensile bond strengths of the tested adhesive systems.

Table 3 Tensile bond strengths of four adhesive systems to bovine dentin in all treating conditions (MPa)

\begin{tabular}{lccccc}
\hline \multicolumn{1}{c}{ Adhesive system } & Control $^{\dagger}$ & $\begin{array}{c}\text { Caries Detector } \\
(\mathrm{r}-\mathrm{a})^{\dagger}\end{array}$ & $\begin{array}{c}\text { Caries Detector } \\
(\mathrm{a}-\mathrm{d})^{\dagger+}\end{array}$ & $\begin{array}{c}1.0 \% \text { acid red aqueous } \\
\text { solution (a-d) }\end{array}$ & $\begin{array}{c}\text { Propylene glycol } \\
(\mathrm{a}-\mathrm{d})^{\dagger+\dagger}\end{array}$ \\
\hline Clearfil Protect Bond $^{\mathrm{a}}$ & $18.1(5.1)$ & $16.6(2.6)$ & $14.8(6.1)$ & $18.8(5.9)$ & $10.3(3.9)^{*}$ \\
Clearfil SE Bond $^{\mathrm{a}}$ & $21.2(4.0)$ & $18.7(3.1)$ & $17.0(3.1)^{*}$ & $19.9(7.1)$ & $12.9(5.9)^{*}$ \\
One-Up Bond F $^{\mathrm{a}}$ & $17.3(4.2)$ & $18.1(3.6)$ & $15.2(1.8)$ & $16.1(4.1)$ & $11.8(4.4)^{*}$ \\
Single Bond $^{\mathrm{b}}$ & $14.2(2.5)$ & $12.9(2.1)$ & $9.4(4.0)^{*}$ & $14.4(2.3)$ & $8.6(3.7)^{*}$ \\
\hline
\end{tabular}

Abbreviations: $r$-a, rinse and air-dry; a-d, air-dry.

All values are indicated as Mean $(\mathrm{SD}) \quad(\mathrm{n}=10)$.

Adhesive systems with the different superscript alphabets are significantly different at $\mathrm{p}<0.05$ using Tukey-Kramer test. Treating conditions with the different superscript symbols $\left(^{\dagger}\right)$ are significantly different at $\mathrm{p}<0.05$ using Tukey-Kramer test.

The superscript symbol $(*)$ indicates significant difference from the control group in each adhesive system at $\mathrm{p}<0.05$ using Dunnett's test. 
In the comparison of treating conditions, the tensile bond strengths of Caries Detector (a-d) and propylene glycol (a-d) groups were significantly lower $(p<0.05)$ than those of the other three groups: Caries Detector (r-a), 1.0\% acid red (a-d), and control groups. Furthermore, the propylene glycol (a-d) group showed significantly lower tensile bond strength $(p<0.05)$ than that of Caries Detector (ad).

In the comparison of adhesive systems, the tensile bond strength of Single Bond was significantly lower $(p<0.05)$ than those of the other three groups.

The tensile bond strengths of two groups, Clearfil SE Bond and Single Bond, showed a significantly lower value $(p<0.05)$ than those of controls when the Caries Detector was air-dried. Then, for all adhesive systems, the propylene glycol (a-d) treatment caused a significant decrease in tensile bond strength $(\mathrm{p}<0.05)$ when compared to the controls.

\section{SEM examination of the fractured specimens}

Table 4 shows the failure modes of the tested adhesive systems to bovine dentin, and Fig. 1 shows the SEM images of the dentin side of the representative fractured specimens.

In all adhesive systems, the failure modes of the control groups were similar to those of Caries Detector (r-a) (Table 4). For Clearfil Protect Bond, cohesive failure in bonding resin was observed in more than half of the specimens in the control, Caries Detector ( $\mathrm{r}-\mathrm{a}$ ), and Caries Detector (a-d) groups (Figs. $1 \mathrm{~A}$ and $1 \mathrm{~B})$. Cohesive failure in bonding resin or the combination of adhesive failure and cohesive failure in bonding resin occurred almost equally in the 1.0\% acid red (a-d) group. On the other hand, adhesive failure and cohesive failure in bonding resin was mainly observed in the propylene glycol (a-d) group.

For Clearfil SE Bond, cohesive failure in bonding resin was observed in more than half of the specimens in the control and Caries Detector ( $r$-a) groups (Figs. 1C and 1D). On the other hand, cohesive failure in bonding resin or the combination of adhesive failure and cohesive failure in bonding resin occurred almost equally in the Caries Detector (a-d), 1.0\% acid red (a-d), and propylene glycol (a-d) groups.

For One-Up Bond F, both adhesive failure and cohesive failure in bonding resin also occurred in more than half of the specimens in the control, Caries Detector ( $\mathrm{r}-\mathrm{a})$, and $1.0 \%$ acid red (a-d) groups (Figs. $1 \mathrm{E}$ and $1 \mathrm{~F}$ ). On the other hand, adhesive failure or the combination of adhesive failure and cohesive failure in bonding resin was observed almost equally in the Caries Detector (a-d) group. Adhesive failure was exhibited in half of the specimens in the propylene glycol (a-d) group.

For Single Bond, adhesive failure was predominant in all groups (Figs. $1 \mathrm{G}$ and $1 \mathrm{H}$ ).

\section{SEM examination of the dentin surfaces}

Typical SEM images of the dentin surface treated with an adhesive system are shown in Figs. 2 and 3.

With all adhesive systems, the specimens of the Caries Detector ( $\mathrm{r}-\mathrm{a}$ ) and $1.0 \%$ acid red (a-d) groups revealed similar images to that of the control group. On the other hand, the images of both Caries Detector (a-d) and propylene glycol (a-d) groups were different from that of the control group.

In all treated dentin surfaces, Clearfil Protect Bond, Clearfil SE Bond, and One-Up Bond F showed similar SEM images. Therefore, the treated dentin surfaces of Clearfil SE Bond are shown in Fig. 2 as typical SEM images. On the specimens of the control, Caries Detector ( $\mathrm{r}-\mathrm{a})$, and $1.0 \%$ acid red (a-d) groups, the dentinal tubules were clearly seen, the smear layer was removed, and the dentinal plugs partially removed (Figs. 2A, 2B, and 2D). In addition, for One-Up Bond $\mathrm{F}$, many small precipitates were observed on the treated dentin surface - which were probably derived from fluoroaluminosilicate glass filler, a component of Bonding Agent B. On the other hand, on the specimens of Caries Detector (a-d) and propylene glycol (a-d) groups, many smear plugs still remained in the dentinal tubules (Figs. $2 \mathrm{C}$ and $2 \mathrm{E}$ )

With Single Bond, which used 35\% phosphoric

Table 4 Failure modes of four adhesive systems to bovine dentin in all treating conditions

\begin{tabular}{lccccc}
\hline \multicolumn{1}{c}{ Adhesive system } & Control & $\begin{array}{c}\text { Caries Detector } \\
(\mathrm{r}-\mathrm{a})\end{array}$ & $\begin{array}{c}\text { Caries Detector } \\
(\mathrm{a}-\mathrm{d})\end{array}$ & $\begin{array}{c}1.0 \% \text { acid red aqueous } \\
\text { solution (a-d) }\end{array}$ & $\begin{array}{c}\text { Propylene } \\
\text { glycol (a-d) }\end{array}$ \\
\hline Clearfil Protect Bond & $0 / 3 / 6 / 0 / 0 / 1$ & $0 / 3 / 5 / 0 / 1 / 1$ & $2 / 2 / 6 / 0 / 0 / 0$ & $0 / 6 / 4 / 0 / 0 / 0$ & $3 / 7 / 0 / 0 / 0 / 0$ \\
Clearfil SE Bond & $0 / 0 / 6 / 0 / 2 / 2$ & $0 / 2 / 6 / 0 / 1 / 1$ & $0 / 4 / 6 / 0 / 0 / 0$ & $0 / 5 / 4 / 0 / 1 / 0$ & $0 / 4 / 6 / 0 / 0 / 0$ \\
One-Up Bond F & $2 / 5 / 2 / 0 / 0 / 1$ & $3 / 5 / 2 / 0 / 0 / 0$ & $4 / 6 / 0 / 0 / 0 / 0$ & $2 / 8 / 0 / 0 / 0 / 0$ & $5 / 2 / 3 / 0 / 0 / 0$ \\
Single Bond & $7 / 0 / 0 / 2 / 0 / 1$ & $6 / 1 / 0 / 3 / 0 / 0$ & $9 / 1 / 0 / 0 / 0 / 0$ & $6 / 2 / 2 / 0 / 0 / 0$ & $9 / 0 / 1 / 0 / 0 / 0$ \\
\hline
\end{tabular}

Abbreviations: r-a, rinse and air-dry; a-d, air-dry.

Number of specimens with the failure mode: adhesive failure/adhesive failure \& cohesive failure in bonding resin/cohesive failure in bonding resin/adhesive failure \& cohesive failure in dentin/cohesive failure in bonding resin \& cohesive failure in dentin/cohesive failure in dentin 

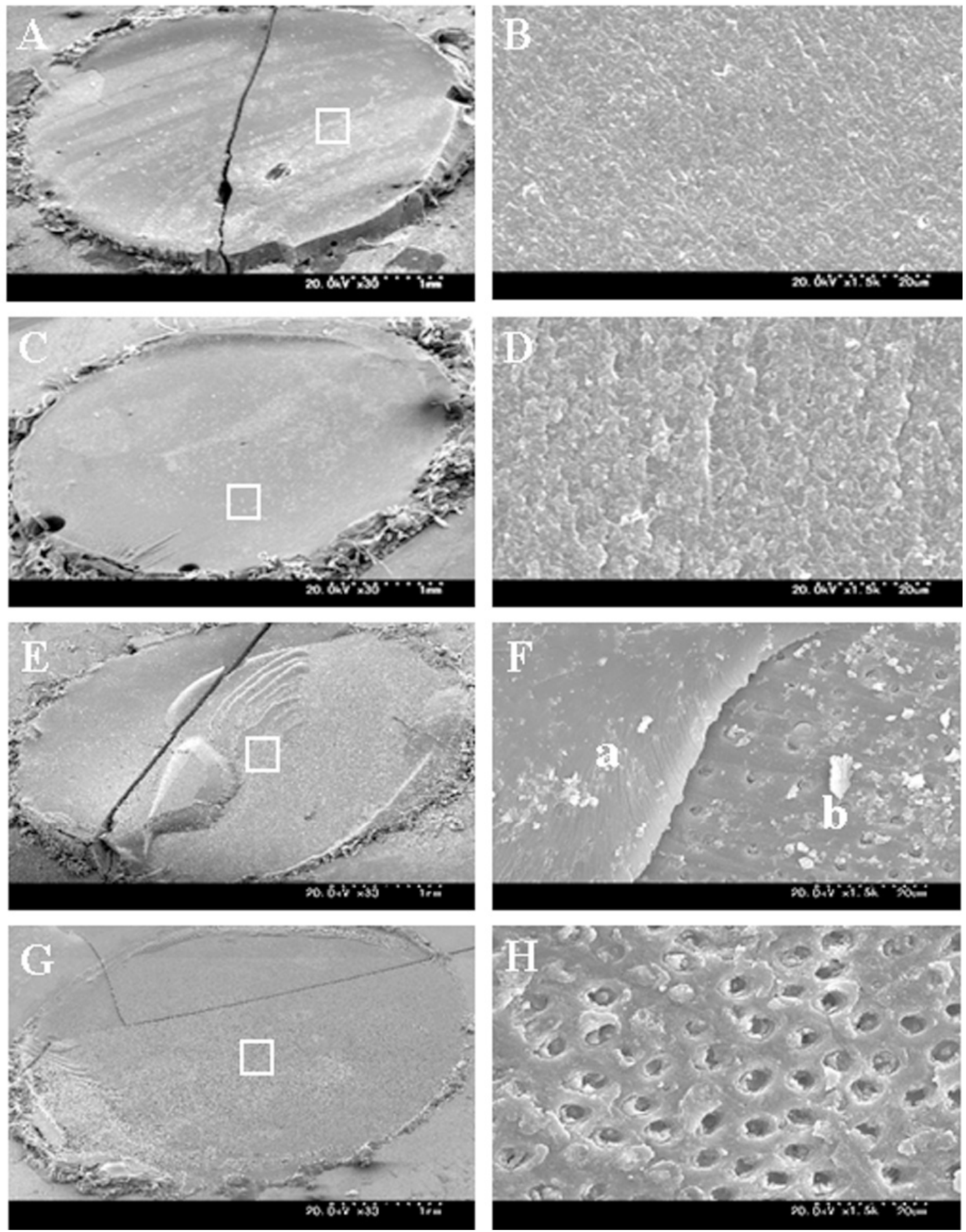

Fig. 1 SEM images of fractured surfaces of the dentin side in Caries Detector ( $r$-a) group (left side: $\times 30$; right side: $\times 1,500$ ), where:

A. Clearfil Protect Bond: cohesive failure in bonding resin

B. Higher magnification of the boxed area in Fig. 1A

C. Clearfil SE Bond: cohesive failure in bonding resin

D. Higher magnification of the boxed area in Fig. 1C

E. One-Up Bond F: adhesive failure and cohesive failure in bonding resin

F. Higher magnification of the boxed area in Fig. 1E

(a: Cohesive failure in bonding resin; b: Adhesive failure)

G. Single Bond: adhesive failure

H. Higher magnification of the boxed area in Fig. $1 \mathrm{G}$ 
acid as etchant, dentinal tubules became wider than those treated with the other three adhesive systems. Smear plugs were fully removed and the intertubular dentin appeared glossy on the specimens of the control, Caries Detector ( $\mathrm{r}-\mathrm{a}$ ), and $1.0 \%$ acid red (a-d) groups (Figs. 3A, 3B, and 3D). On the other hand, on the specimens of Caries Detector (a-d) and pro- pylene glycol (a-d) groups (Figs. 3C and 3E), dentinal tubules were open with a similar diameter as that of the control group. However, smear plugs were not fully removed and the intertubular dentin was rough.
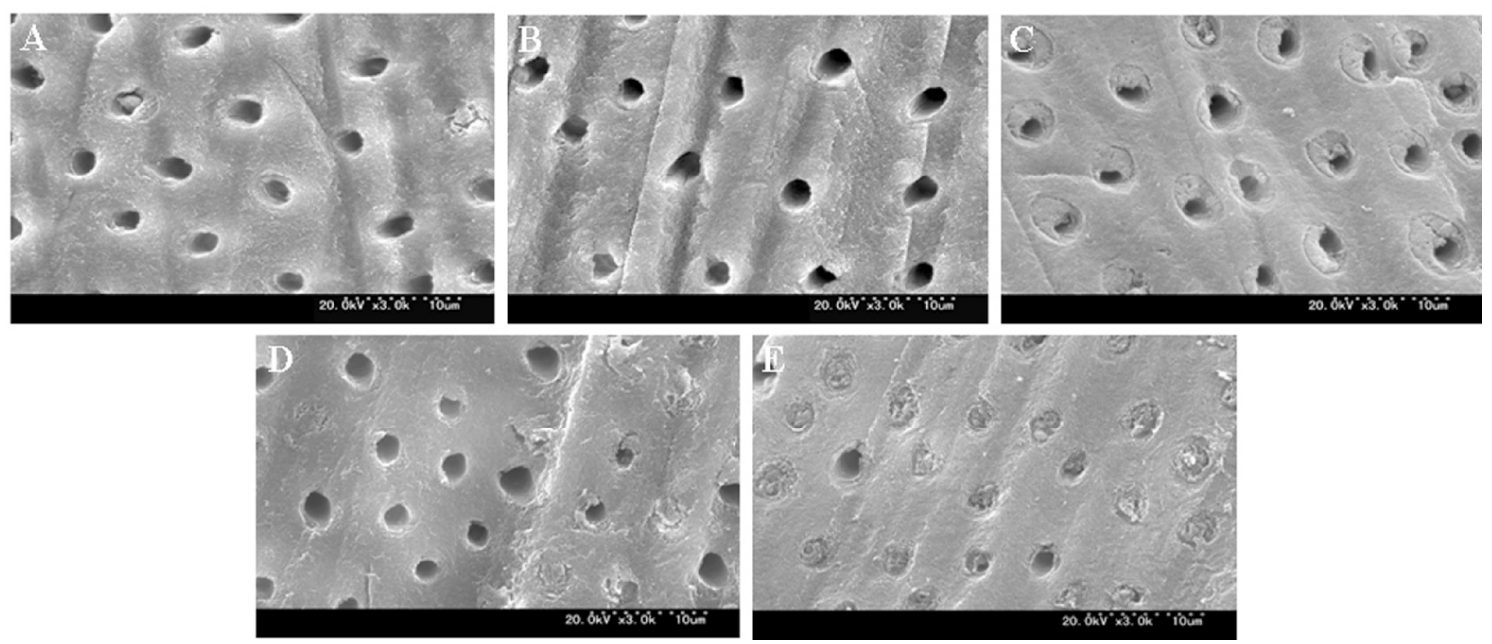

Fig. 2 SEM images of dentin surfaces treated with Caries Detector, 1.0\% acid red aqueous solution or propylene glycol followed by Clearfil SE Bond Primer $(\times 3,000)$, where:

A. Primer

B. Caries Detector ( $r$-a) followed by Primer

C. Caries Detector (a-d) followed by Primer

D. $1.0 \%$ acid red aqueous solution (a-d) followed by Primer

E. Propylene glycol (a-d) followed by Primer
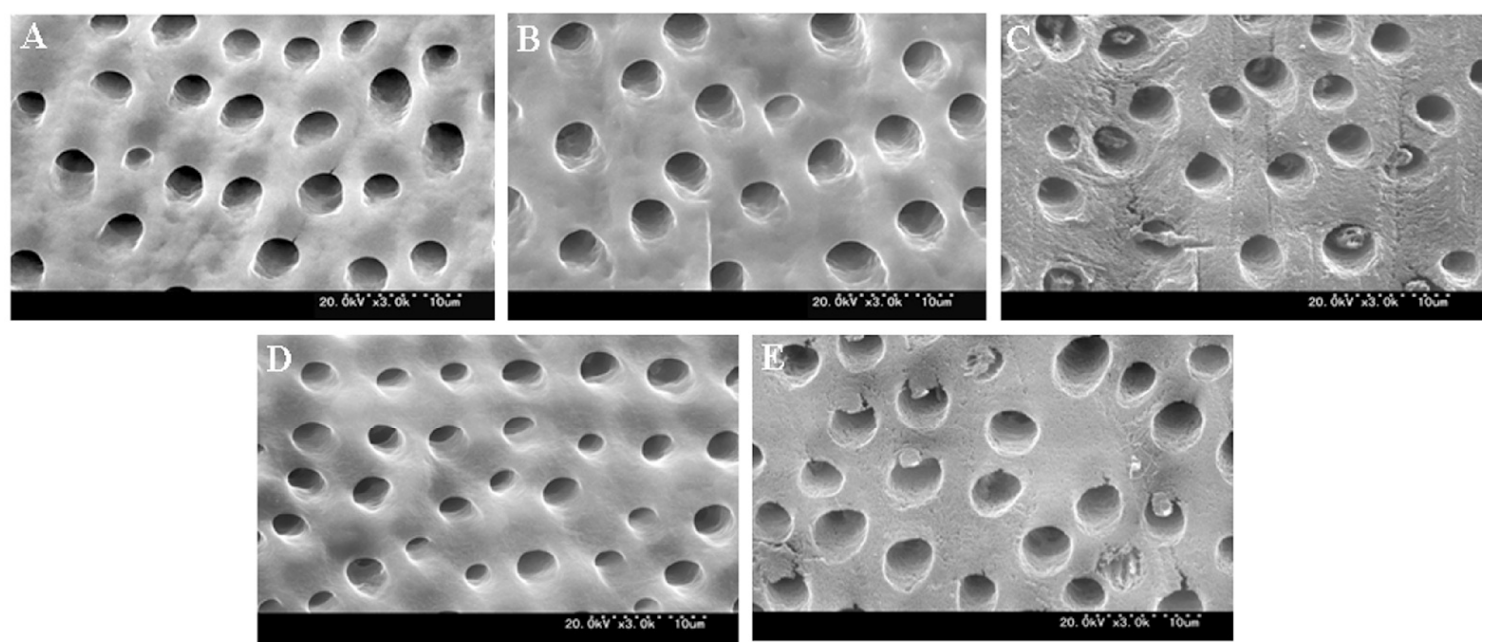

Fig. 3 SEM images of dentin surfaces treated with Caries Detector, $1.0 \%$ acid red aqueous solution or propylene glycol followed by Single Bond Etchant $(\times 3,000)$, where:

A. Etchant

B. Caries Detector ( $\mathrm{r}-\mathrm{a})$ followed by Etchant

C. Caries Detector (a-d) followed by Etchant

D. $1.0 \%$ acid red aqueous solution (a-d) followed by Etchant

E. Propylene glycol (a-d) followed by Etchant 


\section{DISCUSSION}

Caries Detector, a caries-detecting solution, contains $1.0 \%$ acid red in propylene glycol - where the former ingredient is a caries detector dye that stains infected dentin $\operatorname{red}^{7)}$. However, as the property of Caries Detector staining depends on the structural changes of dentin matrix and dentinal tubules ${ }^{35)}$, the surface of caries-affected dentin is stained light pink ${ }^{36)}$.

In this study, sound dentin was stained light pink by Caries Detector. The diffusion of cariesdetecting solution depends on the molecular weight of the solvent used. Since propylene glycol with a small molecular weight was used for the solvent of acid red, the sound dentin used in this study was thought to have been stained. Concerning the substrate for checking the effect of Caries Detector on bond strength, sound dentin was selected due to this chief reason: bond strength to caries-affected dentin is lower than that to sound dentin. Hence, a low bond strength might mask the effect of Caries Detector that remains on the dentin surface.

Despite its application to sound dentin, and even after rinsing and self-etching (or acid-etching), the dye in Caries Detector was not completely removed as evidenced by all specimens with sound tissue stained light pink. However, for all adhesive systems used in this study, the SEM images of the specimens in Caries Detector ( $\mathrm{r}-\mathrm{a}$ ) and control groups indicated no noticeable differences - such as the diameter of dentinal tubule orifice and the appearance of intertubular dentin (Figs. 2A and 2B, 3A and 3B). This was because acid red in propylene glycol dissolves easily in water, and as a result most parts were removed by rinsing. Furthermore, there were no significant differences in tensile bond strength between the Caries Detector ( $\mathrm{r}-\mathrm{a}$ ) and control groups, and the failure modes of the Caries Detector ( $r-a)$ group were similar to those of the control group (Tables 3 and 4). Based on these results, it was thought that the nature of the dentin surface was not affected. These findings also suggested that bonding resin penetrated the conditioned dentin even though traces of Caries Detector remained on the dentin surface. Subsequently, it is likely that a hybrid layer of normal quality could be obtained.

On the other hand, tensile bond strength decreased significantly in all the four adhesive groups when Caries Detector (a-d) contaminated the dentin surfaces (Table 3). SEM images of the dentin surfaces, when treated with self-etching primer or etched with phosphoric acid after the application of Caries Detector (a-d), were different from that of the control (Figs. 2A and 2C, 3A and 3C). When treated with self-etching primer, many smear plugs remained in the dentinal tubules as compared to the control group (Fig. 2C). When etched with phosphoric acid, the diameter of dentinal tubule orifices was compara- ble to that of the control, but the surface texture of the intertubular dentin was rougher than that of the control (Fig. 3C). Concerning the dentin surface after tensile bond test, the results showed that the fracture tendency of the specimens increased toward adhesive failure or the combination of adhesive failure and cohesive failure in bonding resin, when compared to that of the control (Table 4). These findings suggested that when a substantial amount of Caries Detector remained on the dentin surface, it would hinder the infiltration of bonding resin, thereby leading to a decrease in tensile bond strength on the contaminated dentin surface (Table 3).

To investigate the reason why tensile bond strength decreased when Caries Detector was airdried, $1.0 \%$ acid red aqueous solution and propylene glycol were applied separately to the dentin surface and air-dried. Acid red, a main component of Caries Detector, is an edible dye which stains light pink ${ }^{37)}$. After applying $1.0 \%$ acid red solution on the dentin surface and air-dried, followed by the treatment of self-etching primer or phosphoric acid etching, the treated dentin surface was colored thick pink. However, SEM images of the treated dentin surface texture resembled that of the control - in terms of the diameter of dentinal tubule orifices and the appearance of intertubular dentin (Figs. 2A and 2D, 3A and 3D). Furthermore, the tensile bond strengths of these specimens were comparable to that of the control (Table 3). Therefore, it was suggested that acid red did not obstruct bonding to dentin - even when a substantial amount of acid red remained on the dentin surface.

After applying propylene glycol - a solvent of Caries Detector - to the dentin surface and air-dried, the surface was slightly glossy. SEM image of the specimen which was treated with self-etching primer or etched with phosphoric acid was different from that of the control; rather, it resembled the specimen treated with Caries Detector and air-dried (Figs. 2A, $2 \mathrm{C}$ and $2 \mathrm{E}, 3 \mathrm{~A}, 3 \mathrm{C}$ and $3 \mathrm{E})$. From these SEM images, it became clear that when a dentin surface thick with propylene glycol was treated with selfetching primer or phosphoric acid etchant, the degree of demineralization was lower than that of the control. Propylene glycol is a colorless, translucent liquid with a thick consistency. As an alcohol solvent, it melts essential oils and resins ${ }^{38)}$. As it dissolves easily in water and acetone, propylene glycol is easily rinsed away. However, it is difficult to disperse propylene glycol by a gentle stream of air due to its high viscosity. It should be noted that the selfetching primer and phosphoric acid etchant used in this study contained water that could dissolve propylene glycol. Therefore, these agents might have been diluted with the propylene glycol that remained on the dentin surface, resulting in a lower degree of demineralization. With regards to failure mode, the 
specimens demonstrated a higher fracture tendency toward adhesive failure or the combination of adhesive failure and cohesive failure in bonding resin, as compared to the control (Table 4). These findings suggested that when a substantial amount of propylene glycol remained on the dentin surface, it would hinder both resin infiltration into dentin and polymerization, leading to a decrease in tensile bond strength (Table 3 ).

Among the adhesive systems, the tensile bond strength of Single Bond ranked the lowest (Table 3). A previous study has indicated that the tensile bond strength of this adhesive system did not differ significantly from that of self-etching primer systems ${ }^{29)}$. This contradiction was probably due to the wet bonding technique employed in this study, as single-bottle adhesive systems are technique-sensitive ${ }^{39)}$.

In an actual clinical situation, when removal of infected dentin is based on the tactile sense of hardness, such as with a spoon excavator, the decision is very much affected by the operator's skill and experience, as well as by the instrument's sharpness. On the other hand, with a caries-detecting solution, the caries diagnosis and evaluation process assures higher reliability, reproducibility, and objectivity. However, when a substantial amount of Caries Detector remained on the dentin surface, it hindered the adhesion between a resin composite and the dentin. This negative effect would then affect the prognosis of the resin composite restoration. Therefore, the results of this study showed that thorough rinsing and air-drying are indispensably necessary after applying Caries Detector on the dentin.

\section{CONCLUSION}

The effect of a caries-detecting solution on the tensile bond strength of four adhesive systems to sound dentin were investigated in detail in this study. Within the limitations of the present study, the data suggested that the application of a caries-detecting solution (Caries Detector) did not have an undesirable effect on the tensile bond strength to sound dentin when used with self-etching systems or a single-bottle adhesive system - on condition that it was rinsed away thoroughly.

On the other hand, when the dentin surface was contaminated with Caries Detector (i.e., it was not rinsed away), two of the four bonding systems (namely, Clearfil SE Bond and Single Bond) showed a significant decrease in tensile bond strength. It was suggested that one of the ingredients, propylene glycol, affected the tensile bond strength of the four tested adhesive systems. In the light of these findings, care must be taken in clinical situations to rinse away thoroughly the caries-detecting solution after application.

\section{REFERENCES}

1) Tyas MJ, Anusavice KJ, Frencken JE, Mount GJ. Minimal intervention dentistry - A review FDI commission project 1-97. Int Dent J 2000; 50: 1-12.

2) Fusayama T. Painless restoration, Quintessence Publishing Company, Tokyo, 1979, p.14-78.

3) Hosoda H, Kota K, Fukushima M, Kuratate A. Mode of penetration of dentin-adhesive restorative resins into dentin - Concerning a proposition for resin cavities. Niigata Dent J 1979; 9: 107-118.

4) Ogushi K, Fusayama T. Electron microscopic structure of the two layers of carious dentin. J Dent Res 1975; 54: 1019-1026.

5) Kuboki Y, Ohgushi K, Fusayama T. Collagen biochemistry of the two layers of carious dentin. J Dent Res 1977; 56: 1233-1237.

6) Fusayama T. Two layers of carious dentin: Diagnosis and treatment. Oper Dent 1979; 4: 63-70.

7) Fusayama T, Takatsu T, Itoh K, Yamauchi J, Shibatani K. New composition of caries detector. Jpn J Conserv Dent 1979; 22: 261-264.

8) Fusayama T. Clinical guide for removing caries using a caries-detecting solution. Quintessence Int 1988; 19: 397-401.

9) Gwinnett AJ. Quantitative contribution of resin infiltration/hybridization to dentin bonding. Am J Dent 1993; 6: 7-9.

10) Sano H, Shono T, Sonoda H, Takatsu T, Ciucchi B, Carvalho R, Pashley DH. Relationship between surface area for adhesion and tensile bond strength - Evaluation of a micro-tensile bond test. Dent Mater 1994; 10: 236-240.

11) Pashley DH, Sano H, Ciucchi B, Yoshiyama M, Carvalho RM. Adhesion testing of dentin bonding agents: A review. Dent Mater 1995; 11: 117-125.

12) Pashley DH, Carvalho RM, Sano H, Nakajima M, Yoshiyama M, Shono Y, Fernandes CA, Tay F. The microtensile bond test: A review. J Adhes Dent 1999; 1: 299-309.

13) Nakajima M, Sano H, Burrow MF, Tagami J, Yoshiyama M, Ebisu S, Ciucchi B, Russell CM, Pashley DH. Tensile bond strength and SEM evaluation of caries-affected dentin using dentin adhesives. J Dent Res 1995; 74: 1679-1688.

14) Nakajima M, Ogata M, Okuda M, Tagami J, Sano H, Pashley DH. Bonding to caries-affected dentin using self-etching primers. Am J Dent 1999; 12: 309-314.

15) Nakajima M, Sano H, Urabe I, Tagami J, Pashley DH. Bond strengths of single-bottle dentin adhesives to caries-affected dentin. Oper Dent 2000; 25: 2-10.

16) Yoshiyama $M$, Urayama $A$, Kimochi $T$, Matsuo $T$, Pashley DH. Comparison of conventional vs selfetching adhesive bonds to caries-affected dentin. Oper Dent 2000; 25: 163-169.

17) Yoshiyama M, Tay FR, Torii Y, Nishitani Y, Doi J, Itou K, Ciucchi B, Pashley DH. Resin adhesion to carious dentin. Am J Dent 2003; 16: 47-52.

18) Yazici AR, Akca T, Ozgunaltay G, Dayangac B. Bond strength of a self-etching adhesive system to caries- 
affected dentin. Oper Dent 2004; 29: 176-181.

19) Doi J, Itota $T$, Torii $Y$, Nakabo S, Yoshiyama M. Micro-tensile bond strength of self-etching primer adhesive systems to human coronal carious dentin. J Oral Rehabil 2004; 31: 1023-1028.

20) el-Housseiny AA, Jamjoum H. The effect of caries detector dyes and a cavity cleaning agent on composite resin bonding to enamel and dentin. $\mathrm{J}$ Clin Pediatr Dent 2000; 25: 57-63.

21) Demarco FF, Matos AB, Matson E, Powers JM. Dyes for caries detection influence sound dentin bond strength. Oper Dent 1998; 23: 294-298.

22) Oesterle LJ, Shellhart WC, Belanger GK. The use of bovine enamel in bonding studies. Am $J$ Orthod Dentofacial Orthop 1998; 114: 514-519.

23) Schilke R, Lisson JA, Bauss O, Geurtsen W. Comparison of the number and diameter of dentinal tubules in human and bovine dentine by scanning electron microscopic investigation. Arch Oral Biol 2000; 45: 355-361.

24) Nakamichi I, Iwaku M, Fusayama T. Bovine teeth as possible substitutes in the adhesion test. J Dent Res 1983; 62: 1076-1081.

25) Reeves GW, Fitchie JG, Hembree JH, Puckett AD. Microleakage of new dentin bonding systems using human and bovine teeth. Oper Dent 1995; 20: 230-235.

26) Yokota H, Kubo S, Watanabe T, Ohsawa M. Adhesive properties of the fourth generation bonding system Tensile bond strength and characterization of fractured surface. Jpn J Conserv Dent 1996; 39: 1029-1036.

27) Swift EJ Jr, Bayne SC. Shear bond strength of a new one-bottle dentin adhesive. Am J Dent 1997; 10: 184188.

28) Miyazaki M, Sato M, Onose H, Moore BK. Influence of thermal cycling on dentin bond strength of two-step bonding systems. Am J Dent 1998; 11: 118-122.

29) Kubo S, Yokota H, Sata Y, Hayashi Y. Microleakage of cervical resin composite restorations. In: Modern trends in adhesive dentistry proceedings of the adhesive dentistry forum '99 in Tsurumi, Yokohama. Kuraray 2000, Osaka, pp.153-164.

30) Kubo S, Yokota H, Sata Y, Hayashi Y. Microleakage of self-etching primers after thermal and flexural load cycling. Am J Dent 2001; 14: 163-169.

31) Kubo S, Yokota H, Sata Y, Hayashi Y. The effect of flexural load cycling on the microleakage of cervical resin composites. Oper Dent 2001; 26: 451-459.

32) Yokota H, Kawaguchi M, Yokota H, Kubo S, Hayashi Y. Effect of saliva contamination on dentin bond strengths of a self-etching primer system. Jpn J Conserv Dent 2003; 46: 916-924.

33) Hayakawa T, Fukushima T, Nemoto K. Tensile bond strength of 4-META/MMA-TBB resin to ground bovine enamel using a self-etching primer. Dent Mater J 2004; 23: 271-277.

34) Hibino $Y$, Kuramochi K, Harashima A, Honda $M$ Yamazaki A, Nagasawa Y, Yamaga T, Nakajima H Correlation between the strength of glass ionomer cements and their bond strength to bovine teeth. Dent Mater J 2004; 23: 656-660.

35) Sano H. Relationship between Caries Detector staining and structural characteristics of carious dentin. Kokubyo Gakkai Zasshi 1987; 54: 241-270.

36) Fukushima M. Adhesive resin penetration into carious dentin. Kokubyo Gakkai Zasshi 1981; 48: 362-385.

37) The Food Science. Food additive convenient book, 27th ed, The Food Science Co. Ltd., Osaka, 1988, pp.72.

38) Windholz M, Badavari S, Stroumtsos LY, Feritig MN. The Merk Index, 9th ed, Merk \& Co, Rahway, NJ, 1976, pp.1017.

39) Miyazaki M, Onose H, Moore BK. Effect of operator variability on dentin bond strength of two-step bonding systems. Am J Dent 2000; 13: 101-104. 